\title{
EL TALLER Y LA BIBLIOTECA DEL MAESTRO DE OBRAS COMPOSTELANO JOSE DE SEIXAS
}

\author{
por \\ MIGUEL TAÍN GUZMÁN
}

Entre los ricos fondos documentales del Archivo de la Catedral de Santiago, hemos localizado un pleito con el fiscal eclesiástico del arzobispado por el que se exige el cumplimiento de la fundación de ciento veinte misas realizada en 1740 por el maestro de obras compostelano José de Seixas ${ }^{1}$. Entre la documentación adjunta, figura el testamento del artista $(1740)^{2}$ y el inventario meticuloso de sus bienes, según declaración del escribano Pedro Varela de Castro (1744)3.

De su análisis podemos averiguar no sólo la moda del vestir del difunto y su mujer, sino también sus rentas, espíritu atesorador de objetos de lujo, comportamientos consumistas, las manifestaciones de su religiosidad, sus inquietudes artísticas por sus colecciones de tallas, tapicerías, porcelanas, cristalerías, etc., e incluso sus lecturas y nivel cultural ${ }^{4}$.

De todo ello, nos interesan particularmente los datos referentes al ta-

\footnotetext{
${ }^{\prime}$ Archivo de la Catedral de Santiago, El fiscal eclesiasttico y de obras pias de estte arzobispado con Don Pedro Varela de Castro, scribano vezino de esta ciudad, sobre cumplimientto de misas de fundazion que dexo Joseph de Seixas, maestro de obras, por su testtamentto vajo cuia disposizion murio. Ciuil. Año de 1740, Pleitos s. XVIII, N'I.

${ }^{2}$ Fols. 2r.-6v.

${ }^{3}$ Fols. $75 \mathrm{v} .-84 \mathrm{r}$.

${ }^{4}$ Cfr. BENNASSAR, B.: «Los inventarios post-mortem y la historia de las mentalidades», La documentación notarial y la historia, Actas del II coloquio de Metodología Histórica Aplicada, Universidad de Santiago, 1984, t.II, 139-146.
}

"CUADERNOS DE ESTUDIOS GALLEGOS", Tomo XLI, Fascículo 106, Santiago 1993-94. 
ller y la biblioteca. En un caso, por ser los primeros conocidos de un maestro de obras de esta época; en el otro, porque aún conociendo algunas bibliotecas de arquitectos de la segunda mitad del siglo XVII -las de Francisco de Antas $^{5}$ y Diego de Romay ${ }^{6}$, y algunos libros de Domingo de Andrade ${ }^{7}-$ apenas sí tenemos datos sobre las del siglo siguiente si exceptuamos las relativas a la biblioteca de Fernando de Casas y Novoa $^{8}$, y a algunos libros de Simón Rodríguez y de Lucas Ferro Caaveiro ${ }^{10}$.

\section{1-NOTAS BIOGRAFICAS}

Pocas son las noticias biográficas que conocemos de este autor, que no aparece citado ni en la obra de Murguía ${ }^{11}$ ni en el diccionario de Couselo Bouzas $^{12}$.

${ }^{5}$ Archivo Histórico de la Universidad de Santiago, Prot. A. Camino de Marín, leg. 2355, 1664, fols. 70 y ss. Véase GASALLA FERNANDEZ, L.: Aportación documental sobre a actividade artística compostelana entre 1649 e 1686, Tesis de licenciatura inédita, Santiago, 1991, 56-64, 162-185. La biblioteca y papeles del arquitecto fueron vendidos a su muerte a la Fábrica de la Catedral de Santiago, pudiendo ser consultados desde entonces por los canónigos y probablemente también por los treinta y nueve ministros catedralicios, entre los que se encontraban el maestro y el aparejador de obras (A.C.S., Libro II de Fábrica, n534, fol. 127v.).

${ }^{6}$ A.H.U.S., Prot. Vázquez Mosquera, leg. 2595, 1694, fols. 85 y ss.

7 TAIN GUZMAN, M.: Comentario a las Excelencias, Antigvedad, y Nobleza de la arquitectura de Domingo de Andrade, Santiago, 1993, 17-18, 45-50, 53-54, 83-96.

${ }^{8}$ FOLGAR DE LA CALLE, M${ }^{\mathrm{a}}$. DEL C.: «Un inventario de bienes de Fernando de Casas», Cuadernos de Estudios Gallegos, 1982, 535-547.

${ }^{9}$ Con el ex libris del arquitecto, he localizado en la Biblioteca Universitaria, bajo la signatura R.S.E.2100, la obra de A. DE CEPEDA Y ADRADA: Epitome de la fortificacion moderna (Bruselas, Francisco Foppens, 1669).

${ }^{10} \mathrm{Con}$ el ex libris del arquitecto, he localizado en la Biblioteca Universitaria, y con la signatura 23.589, la segunda parte de la obra de FRAY LORENZO DE SAN NICOLAS: Arte y vso de architectura (Madrid, Juan Sánchez(?), 1665). El tomo de la primera parte (Madrid, Bernardo de Hervada, 1667), con la signatura 23.588, es muy probable que también perteneciera a Caaveiro pues tiene la misma encuadernación en cuero y el mismo tipo de decoración en el lomo con motivos vegetales y geométricos dorados. Es en este último ejemplar donde A. BONET CORREA («Un soneto sobre Diego de Romay», Cuadernos de Estudios Gallegos, 1957, 298-300) descubrió un poema dedicado a Diego de Romay. Nos preguntamos si el mismo fue escrito por el artista dieciochesco.

"MARTINEZ MURGUIA, M.: El arte en Santiago durante el siglo XVIII y noticia de los artistas que florecieron en dicha ciudad y centuria, Madrid, 1884.

${ }^{12}$ COUSELO BOUZAS, J.: Galicia artística en el siglo XVIII y primer tercio del XIX, Compostela, 1932.

"CUADERNOS DE ESTUDIOS GALLEGOS", Tomo XLI, Fascículo 106, Santiago 1993-94. 
Maestro de obras, era vecino de la parroquia compostelana de Santa Susana, en el Barrio del Pombal, zona en la que residían un gran número de artistas compostelanos. Hacia 1694 se casó con Dominga Vázquez, no teniendo descendencia ${ }^{13}$. Hombre muy piadoso, manda decir, desde 1700, una misa rezada todos los viernes del año en el altar de Nuestra Señora de la Soledad de la Catedral ${ }^{14}$, y dota con rentas a algunas doncellas para que puedan contraer matrimonio. Además, por su testamento sabemos que fue cofrade y mayordomo de las cofradías del Apóstol Santo Tomé y del Patriarca San José -ambas, hermandades corporativas integradas por carpinteros, escultores, entalladores, canteros, pedreros y maestros de obras de la ciudad- ${ }^{15}$, y de las del Santo Angel y Benditas Animas del Purgatorio; cofrade y vicario de la cofradía de Santa Margarita, y únicamente cofrade en la de San Mauro.

Falleció pocos días después de expresar su última voluntad por escrito, siendo enterrado en la Capilla de la Venerable Orden Tercera de San Francisco con hábito franciscano y asistido por las cofradías de la Concepción, Santo Tomé Apóstol, el Patriarca San José y las comunidades de San Francisco, San Lorenzo, Santo Domingo y San Agustín, celebrándose ese día cuarenta misas de sufragio ${ }^{16}$.

En su testamento deja algunos bienes a varios familiares y a una criada, siendo su mujer la heredera universal del resto de sus pertenencias. Sin embargo, autoriza a sus albaceas a gravar o vender todos las propiedades necesarias para establecer y cumplir una abultada fundación de misas, a celebrar «en los dos actos de septimo dia» y cada cabo de año por los franciscanos y algunas cofradías de la ciudad. El incumplimiento de esta fundación generará el pleito, que es el motivo último que provocó la redacción del inventario ${ }^{17}$.

\footnotetext{
${ }^{13}$ En el testamento declara «...que abra vnos quarenta y seis años poco mas o menos me allo casado...». Fol. 3v.

${ }^{14} \mathrm{Y}$ que por su testamento perpetúa, junto con otras de nueva creación en el altar mayor de la Capilla de las Animas del convento de San Francisco. Fol. 4r.v.

${ }^{15}$ Sobre estas cofradías véanse GASALLA FERNANDEZ, L: op. cit., 32-36; RODRIGUEZ GONZALEZ, A.: «Cofradías y gremios de Santiago (1771)», Compostellanum, 1986, 471.

${ }^{16} \mathrm{El}$ pleito contiene los recibos de los gastos del funeral.

${ }^{17}$ Cfr. GONZALEZ LOPO, D.: «La actitud ante la muerte en la Galicia occidental de los siglos XVII y XVIII», La documentación notarial y la historia, Actas del II coloquio de metodología histórica aplicada, Universidad de Santiago, 1984, t.II, 125-137; Idem: «Un aspecto de la mentalidad religiosa gallega de los siglos XVII y XVIII: la fundación de obras pías», Jubilatio I, 363-373.
}

"CUADERNOS DE ESTUDIOS GALLEGOS", Tomo XLI, Fascículo 106, Santiago 1993-94. 
Desarrolla su actividad profesional coetáneamente a los grandes maestros compostelanos Fernando de Casas y Novoa y Simón Rodríguez. Sin embargo, pese a saberse que tenía taller propio con oficiales a su cargo, un conocimiento teórico de su profesión a través de los tratados de arquitectura de su pequeña biblioteca, un importante patrimonio adquirido «...con las muchas y grandes obras que tubo siempre a su cuidado tanto en esta ciudad como fuera de ella ${ }^{18}$, su pertenencia a la élite de la cofradía del Patriarca San José, y que realizaba «bisttas oculares» de obras de otros maestros ${ }^{19}$, apenas sí tenemos datos de sus intervenciones profesionales. En compañía de Alonso da Pena, Juan de Yllobre, Jerónimo García, Pedro Mosquera, Antonio Remesar, Juan Alvarez, Jacinto Gómez y Andrés de Bucide, maestros y oficiales de carpintería, se encuentra en 1707 ocupado en un polémico tablado y cierre para las corridas toros que se proyectaban celebrar en las fiestas en honor «al feliz parto de la Reina nuestra Señora y nacimiento de su Alteza Real el Señor Principe de Asturias», en la Plaza de Azabachería ${ }^{20}$. En 1713 se le paga la reparación de «las puertas y tableros» de las tiendas de la Plaza de las Platerías, que realiza asociado con el también carpintero Pedro Blanco ${ }^{21}$. También, de esta época debe ser el encargo del concejo de la ciudad para que construya un tablado enfrente de la fachada del Hospital Real con el fin de que sus miembros puedan asistir a las corridas de toros de la plaza el día del Apóstol ${ }^{22}$. En estos tres documentos se designa a Seixas simplemente como carpintero, debido probablemente a que corresponden al comienzo de su carrera profesional. En 1717, cuando ocupa la silla arzobispal Luis de Salcedo y Azcona, contrata la reparación de los desperfectos del Palacio Arzobispal ${ }^{23}$. Nada conocemos de sus actividades posteriores a esa fecha hasta el año de su muerte en que se encuentra construyendo dos casas de la Rúa del Villar, una para el Marqués de Montesacro y otra para una mujer «del Riuero» ${ }^{24}$.

\footnotetext{
${ }^{18}$ Fol. $44 \mathrm{v}$.

${ }^{19}$ Fol. 63 r.

${ }^{20}$ A.C.S., Legajo $\mathrm{n}^{\circ} 358$.

${ }^{21}$ A.C.S., «Gastos extraordinarios de la Messa Cappitular del año de 1712», 37, del Libro de Hacienda, 1710 a 1717, $\mathrm{n}^{\circ} 547$.

${ }^{22}$ Archivo Histórico Nacional, Sección Consejos, Legajo n¹7.207. En el documento se indica que a Seixas se le conocía popularmente como «Chancas».

${ }^{23}$ Fol. 80v.

${ }^{24}$ Fol. 54r.
}

"CUADERNOS DE ESTUDIOS GALLEGOS", Tomo XLI, Fascículo 106, Santiago 1993-94. 


\section{2-PROPIEDADES}

Es interesante la lectura y estudio del testamento e inventario de los bienes de José de Seixas, calificados en la documentación como «los correspondientes a cassa de vn oficial honrrado de su estado y esfera», porque, a través de su patrimonio, llegamos a deducir su nivel económico, pudiéndolo incluir entre los miembros de una clase media acomodada de la Compostela del siglo XVIII' ${ }^{25}$.

Sorprende el enorme número de bienes raíces, y que conocemos, sobre todo, por la pormenorizada enumeración que se hace de los mismos en el documento de su postrera voluntad. El maestro poseía al final de su vida diez casas, distribuidas en distintos barrios de la ciudad ${ }^{26}$.

Todas, a excepción de su vivienda, estaban alquiladas y le rendían pingües beneficios. También era dueño de tierras arrendadas en las feligresías de San Juan de Cambeda (Vimianzo) y San Martín de Olveira (Dumbría). La práctica de invertir en la compra de viviendas y tierras, que luego se aforaban, era un hecho corriente entre los artistas compostelanos y suponía una fuente de ingresos suplementaria.

De su casa se ha confeccionado un detallado inventario de todos los enseres, habitación por habitación, que recoge sus muebles (bufetes, arcas, taburetes de «moscovia», una cama, etc.), ropas de vestir y ajuar domésti$\mathrm{co}$, $\operatorname{armas}^{27}$, objetos de cobre, bronce y plata ${ }^{28}$, un pequeño número de

${ }^{25}$ Similar conclusión se extrae del análisis del inventario de bienes del arquitecto Fernando de Casas. Cfr. FOLGAR DE LA CALLE, Mª DEL C.: art. cit., 536.

${ }^{26}$ Una en la Rúa del Franco, otra en Puerta Faxeiras, una tercera en la Carrera del Conde, otra extramuros que era en realidad un horno y se hallaba inmediata a la mencionada puerta, y seis en el barrio del Pombal, en una de las cuales residía el maestro y su familia, y en otra «...que se alla junto al crucero... es la en que biuio y murio Don Domingo de Andrade, Maestro de obras que fue de la Santa Apostolica Yglesia de Señor Santiago».

27 «Vna carauina» y «vna espada ancha con su concha y puño de hilo de azofar, vsada».

${ }^{28}$ La posesión de éstos últimos era símbolo de cierto acomodamiento social: «Cattorçe cucharas y cattorçe thenedores de platta moda anttigua», «Vn platillo, vn salero y vna jarra, todo de platta. Vna saluilla con su pie tanuien de platta», «dos caxas de platta, vna antigua y la ottra de la moda».

"CUADERNOS DE ESTUDIOS GALLEGOS", Tomo XLI, Fascículo 106, Santiago 1993-94. 
imágenes ${ }^{29}$, cuadros $^{30} \mathrm{y}$ láminas ${ }^{31}$, una modesta biblioteca, algún dinero, $\mathrm{y}$ utensilios de la cocina (vajilla), bodega (arcas y barriles), «tienda» y taller.

\section{3-EL TALLER}

Seixas declara en su testamento que en el mismo barrio del Pombal, un poco más abajo de su casa, posee otra «...donde tengo el taller de mi oficio, que se alla baluada en treinta y dos ducados de renta cada año». El edificio, aparte del obrador, «donde tenia los oficiales», contenía una vivienda, entonces alquilada al escribano Pascual Antonio Tubio.

Por el inventario de bienes conocemos la lista de los enseres allí almacenados, todos ellos materiales de construcción: «Nueue tablas de obra. Sesentta y cinco de medio filo. Trescientas y nouentta de asientto. Honçe de alamo. Pontones de ocho, y diez, y cattorçe, veintte y cinco de largo. Cinco soleras de lo mismo. Diez ponttones y honze tablas tanuien de alamo».

En el taller, los oficiales debían preparar la madera, secándola y desbastándola, para luego utilizarla en la reparación o construcción de edificios contratados en la ciudad ${ }^{32}$. Al contrario que en registros de bienes de otros maestros de obras compostelanos ${ }^{33}$, nuestra documentación es parca

\footnotetext{
${ }^{29}$ «Dos ymagenes de bultto de Nuestra Señora, la una la Axsension y la ottra la Angusttia con su hijo en los braços», «vna efixie de Santto Chrisptto de madera», «vna efixie de San Joseph con el niño en los brazos de yeso, con su escaparatte de madera pinttado con sus bidrios» y «vna efixie de Santta Margaritta en papel con su marco de madera de casttaño».

${ }^{30}$ «Vn quadro de San Joseph», «ottro de San Francisco (y) San Marcos» y «ottra pinttura del rico abarientto sin marco».

${ }^{31}$ «Tres laminas en papel, la una efixie de la Muerte, ottra la Madre Dolorosa y la ottra el Exseomo, con sus marcos de madera enbutidos en gueso», «otras dos esttampas de papel de Christto crucificado y Nuestra Señora con el niño, con sus marcos de madera de casttaño», «vna laminitta del Niño Jesus bordada, con marco negro» y «ottro de la Axsension de Nuesttra Señora en papel, con marco negro vieja». Tanto las láminas como las imágenes y los cuadros presentan una iconografía similar a la que aparece en los inventarios post mortem de la centuria anterior. Cfr. ROZADOS FERNANDEZ, $M^{a}$ DE LOS A.: «La iconografía religiosa a través de los inventarios post mortem: Santiago de Compostela en el s. XVII», Compostellanum, 1986, 411-416.

${ }^{32}$ Sobre algunos talleres de maestros compostelanos véase GASALLA FERNANDEZ, L: op. cit., 26-29.

${ }^{33}$ Véase FOLGAR DE LA CALLE, Ma ${ }^{\mathrm{a}}$. DEL C.: art. cit., 537.
}

"CUADERNOS DE ESTUdiOS GALLEGOS", Tomo XLI, Fascículo 106, Santiago 1993-94. 
a la hora de enumerar los instrumentos que debía utilizar Seixas en su profesión: "Vn tinttero, salvadera y obleera de esttaño», utilizados para sus escritos y probablemente también para sus dibujos, «tres marttillos de hierro» y «vna sierra para refender».

\section{4-LA BIBLIOTECA}

Sobre «vn esttante para libros, de madera de alamo», del dormitorio, se encontró una pequeña biblioteca constituida por quince títulos y veinticinco tomos. La misma, testimonia en nuestro caso las inquietudes intelectuales del propietario y el hecho de que sabía leer. Estos libros le servían de lectura, ocio y estudio, y, en algunos casos, para resolver problemas técnicos de su profesión.

En el inventario, de cada libro se indica el título, a veces el autor, y siempre el tamaño, lo cual, permiten que sean fáciles de identificar. Aunque no se indica ni el lugar ni la fecha de edición, podemos suponer por el documento que se tratan de ediciones en castellano.

Por su temática podemos agruparlos en cinco apartados: libros religiosos, de literatura, de leyes, de historia y de arquitectura.

\subsection{Libros religiosos}

Los textos de contenido religioso y de devoción son los dominantes, algunos de ellos con claro interés iconográfico, como en el caso de los dos pimeros tomos del Flos Sanctorum de Alonso de Villegas ${ }^{34}$, algunas de cuyas ediciones se acompañan de un rico repertorio de ilustraciones ${ }^{35}$.

\footnotetext{
${ }^{34}$ «El primero y segundo tomo de Flox Santtorum de Villegas, de a folio». Consideramos oportuno indicar en esta nota, y las sucesivas, los títulos que en el inventario aluden a cada uno de los textos.

${ }^{35}$ La primera parte, bajo el título «Flos Sanctorum Nuevo y Historia General de la vida y hechos de Iesu Christo... y de todos los Sanctos de que reza y haze fiesta la Iglesia Catholica, conforme Breviario Romano...», estudia la vida de los santos basándose en los escritos de Lipomano y Surio, y en la Legenda Aurea de Santiago de Vorágine, siendo publicada en Toledo en 1578 y reimpresa en Zaragoza (1580 y 1621), Toledo (1582 y 1591), Madrid (1588, 1594, 1652 y 1721), Gerona (1587), Barcelona (1585 y 1593), Iuli Puebla en Chucuyto (1612), y Valladolid (1625). La Segunda Parte, «Flos Sanctorum, Segvnda Parte, y Historia General, en que se escrive la vida de la Virgen Sacratissima Madre de Dios, y Señora nuestra y las de los Santos antiguos, que fueron antes de la venida de nuestro Salvador al mundo», analiza la vida de la Virgen y de los santos anterio-
}

"CUADERNOS DE ESTUDIOS GALLEGOS", Tomo XLI, Fascículo 106, Santiago 1993-94. 
Pero, además, el inventario cita un tercer tomo del Flos Sanctorum, esta vez sin indicar el autor ${ }^{36}$. Quizás se trate, otra vez, de Villegas, quien aun tiene publicadas una Tercera y Cuarta parte de su obra, sin embargo, no debemos descartar otras posibilidades, pues con este mismo título se venían publicando desde el siglo XV repertorios de vidas de santos ${ }^{37}$.

También pertenece a este grupo el texto de sor María de Agreda «Mystica Ciudad de Dios» ${ }^{38}$, uno de los relatos más detallados, piadosos y fantasiosos que se hayan escrito nunca sobre la vida de la Virgen, que pretendiendo ser el resultado de un contacto directo y continuo de la religiosa con la Madre de Cristo, es en realidad una reactualización de todos los viejos Apócrifos, lo que provocó su prohibición por la Inquisición española (1672) y por el Santo Oficio de 1681-1686, y la condena de la Universidad de la Sorbona $(1696)^{39}$.

De índole diferente son las siguientes obras que completan este capítulo. El «Promptvario de las indulgencias... excelencias... y privilegios con

res a la venida de Cristo, y las ediciones conocidas son las de Toledo (1588-89 y 1594), Barcelona $(1586,1587,1589,1600,1612,1691,1696)$, Alcalá de Henares $(1609,1619)$, Lisboa (1609 y 1625), y Madrid (1657, 1673 y 1721). Sin embargo, en vista de las fechas del privilegio, aprobaciones y licencias, la edición príncipe debe datar de 1583 o 1584 . Cfr. HORNEDO, R.M. DE: «Villegas, Alonso de», Diccionario de historia eclesiástica de España, t.IV, Madrid, 1975, 2766-2767; PALAU Y DULCET, A.: Manual del librero hispanoamericano, t.XXVII, Barcelona, 1976, 253-261.

${ }^{36}$ «Vn tomo de Flox Santtorum en prosa o cadenzia, sin principio ni posttre».

${ }^{37}$ Tales son los casos de Fray Martín de Lilio, de Pedro de la Vega, de Martín de Roa, o del jesuita Pedro de Ribadeneyra. Cfr. HORNEDO, R.M. DE: op. cit., 2767; MADRID, I. DE: «Vega, Pedro de la», Diccionario de historia eclesiástica de España, t.IV, op. cit., 2720. PALAU Y DULCET, A.: op. cit., t.V, 441-442; Idem: t.XVI, 436-446; t.XXV, 412413; REY, E.: «Ribadeneyra, Pedro de», Diccionario de historia eclesiástica de España, t.III, 2085; SIMON DIAZ, J.: Impresos del Siglo XVII, Madrid, 1972, 164.

${ }^{38}$ «Nueue libros de octtauo de la Misttica Ciudad de Dios».

${ }^{39}$ «Mystica Ciudad de Dios, Milagro de su Omnipotencia, y Abismo de la Gracia. Historia Divina y Vida de la Virgen Madre de Dios, Reyna, y Señora Nvestra, Maria Santissima, Restavradora de la cvlpa de Eva, y Medianera de la Gracia, manifestada en estos ultimos siglos por la misma Señora a su Esclava..., abadesa del convento de la Inmanculada Concepción de la Villa de Agreda». Imprimiéndose por primera vez en Madrid en 1670, fue reeditada en infinidad de ocasiones: Lisboa (1681), Perpiñán (1684), Madrid (1688, 1701, 1720, 1721, 1725, 1730), Barcelona (1689, 1694-95), Valencia (1695) y Amberes $(1692,1696,1705,1708,1722,1736)$. Cfr. PALAU Y DULCET, A.: op. cit., t.I, 93-95; PEETERS-FONTAINAS, J.: Bibliographie des impressions espagnoles des PaysBas Méridionaux, t.I, Nieuwkoop, 1965, 8-13; VAZQUEZ, I.: «Agreda, María de Jesús de», Diccionario de historia eclesiástica de España, t.I, 14.

"CUADERNOS DE ESTUDIOS GALLEGOS", Tomo XLI, Fascículo 106, Santiago 1993-94. 
que se ilustra el Serafico Instituto de la V. Orden Tercera $\rangle^{40}$, obra del religioso gallego Buenaventura Tellado, es un pequeño libreto, publicado en Salamanca en 1719 y 1730 , donde se narra la historia y regla de la Orden a partir de las indulgencias recibidas de los Papas, particularmente de Inocencio XI e Inocencio XII ${ }^{41}$. El «Libro de quatuor nouisimvs que quiere dezir de los quatro postreros trances, traducido de latin por un monge de la misma profesion Cartuxana», escrito por el cartujo Dionisio Rickel y publicado en Toledo en $1548^{42}$. El anónimo «Devocionario del Santissimo Sacramento y de Nuestra Señora, y de otros Santos», publicado en Madrid en 1667, libro de oraciones y prácticas piadosas de uso habitual por los fieles ${ }^{43}$. Y el último, que se relaciona como «Conpendio para los hijos de la Terçera Horden, en ottro tomo de octtauo», creemos que pudiera tratarse de la obra recogida en el manual de Palau y Dulcet, sin especificación de autor, como «Compendio de las indulgencias de la Tercera Orden Franciscana», texto publicado en Madrid en $1714^{44}$.

\subsection{Literatura}

Un solo libro de literatura recoge el inventario ${ }^{45}$. Se trata de la publicación del repertorio de poesías presentadas en 1697 al certamen organizado por la Universidad de Santiago el día dedicado a su fundador, Alonso de Fonseca, y que se dió a conocer con la difusión del «Cartel del Certamen Olimpico de las Fiestas Minervales». Fruto del concurso fue un libreto que comienza con una «Introduccion al Certamen Olympico» -que había contado con la participación de más de cien poetas (Fray Plácido Mosquera, J. Vallo de Porras, I. Leal de Seronde, J. Villaran, Fray Gabriel Noboa, etc.) de Galicia, Salamanca, Madrid, Valladolid, Oviedo, León, Toledo, Toro y Alcalá- y que presenta a continuación las composiciones premia-

${ }^{40}$ «Tellado Pronttuario, en vn tomo de a quartto».

${ }^{41}$ «Promptvario de las indulgencias que goza excelencias con que se engrandece y privilegios con que se ilustra el Serafico Instituto de la V. Orden Tercera de Penitencia de N.Ser.P. San Francisco, util para todo genero de personas, religiosas, eclesiasticas, y seculares». Cfr. PALAU Y DULCET, A.: op. cit., t.XXIII, 32; «Tellado, Buenaventura», Gran Enciclopedia Gallega, t.XXIX, 64.

42 «Los Quatro Nouisimos, en un tomo de octauo». Cfr. PALAU Y DULCET, A.: op. cit., t.XVI, 486.

${ }^{43}$ «Debocionario del Santtisimo Sacramento, Nuesttra Señora y ottros santtos, en un tomo de octtauo». Cfr. PALAU Y DULCET, A.: op. cit., t.IV, 387.

${ }^{44}$ Cfr. PALAU Y DULCET, A.: op. cit., t.III, 617.

${ }^{45}$ «Serttamen Olimpico, en un tomo de a quartto».

"CUADERNOS DE ESTUDIOS GALLEGOS", Tomo XLI, Fascículo 106, Santiago 1993-94. 
das, todas en verso y algunas en lengua gallega ${ }^{46}$.

\subsection{Leyes}

Este apartado también cuenta con un único ejemplar titulado «Consttittuziones del Gran y Real Ospittal de esta ciudad, en un tomo de a quartto», que pueden ser las dadas por Carlos V en 1524 o las emitidas por Felipe II en 1590. Sabemos de otra edición posterior llevada a cabo en Santiago por el impresor Juan Jaque, el 9 de julio de $1640^{47}$.

\subsection{Historia}

Dos obras conforman este apartado. La primera es la de Jean Bussieres «Ramillete de Flores Historiales, recogido de los mas señalados sucessos que ha visto el mundo desde su. Creacion hasta nuestros tiempos», cuyo original fue redactado en latín, pero que Seixas pudo conocer a través de la traducción de Lorenzo Matheu y Sanz editada en Valencia (1655) y Madrid (1666). El texto narra los sucesos históricos memorables desde tiempos de Jesucristo hasta el rey Carlos $\mathrm{II}^{48}$.

Y la segunda es un escrito de Carlos Coloma que lleva por título «Las Gverras de los Estados Baxos desde el año de mil y qvinientos ochentay ocho, hasta el de mil quinientos nouenta y nueve», editado en Amberes $(1625,1629$ y 1635$)$ y Barcelona (1627). En ella se narran, en doce capítulos, las campañas militares de los ejércitos españoles en los Países Ba

El título de la publicación resultante es el de «Fiestas Minervales, y aclamacion perpetua de las Musas, à la inmortal memoria de el Ilustrissimo, y Excelentissimo Señor D. Alonso de Fonseca El Grande, Arzobispo de Toledo, y de Santiago, por sv Escvela, y Vniversidad, que afectvosamente las consagra, dedica, y ofrece, al Excelentissimo Señor Conde de Monte-Rey, su Protector, Valedor, y Mecenas» (Santiago, Antonio Frayz, 1697). Cfr. ALONSO MONTERO, X.: «Estudio literario das Festas Minervais compostelanas de 1697», estudio que acompaña a la edición facsímil de «Fiestas Minervales» publicada por la Universidad, Santiago, 1993; BUSTAMANTE Y URRUTIA, J.Mª DE: op. cit., t.II, 286-287. CABEZA DE LEON, S.: «Lo que costó a la Universidad de Santiago una fiesta literaria en 1697», Boletín de la Real Academia Gallega, 1917, t.XI, 100-103, 127-135; Idem: Historia de la Universidad de Santiago de Compostela, t.I, Santiago, 1945, 470473; «Fiestas Minervales», Gran Enciclopedia Gallega, t.XIII, 10-11; LOPEZ, A.: La imprenta en Galicia. Siglos XV-XVIII, Madrid, 1953, 134-140.

${ }^{47}$ Cfr. ALVAREZ, M.L.: «Hospital de los Reyes Católicos», Gran Enciclopedia Gallega, t.XVII,170-180; LOPEZ, A.: op. cit., 79 y 84.

${ }^{48}$ «Ramillette de Flores, en un tomo de octtauo». Cfr. PALAU Y DULCET, A.: op. cit., t.II, 478 .

"CUADERNOS DE ESTUDIOS GALLEGOS", Tomo XLI, Fascículo 106, Santiago 1993-94. 
jos desde el año 1588 hasta 1599, en que se instalaron en Bruselas los archiduques $^{49}$.

\subsection{Libros de arquitectura}

Este quinto bloque estaría formado por cuatro obras de arquitectura. Una de un autor clásico, Vitruvio, dos de autores barrocos, Fray Lorenzo de San Nicolás y Juan de Torija, y, finalmente, una cuarta de autor de difícil identificación.

$\mathrm{El}$ «De architectura» de Vitruvio es un texto del siglo I a. J.C., redescubierto en Italia y publicado por primera vez en latín en 1486. Momento a partir del cual se iba a convertir en una especie de Biblia para los artistas del Renacimiento. Su autor, que nos ha llegado precedido de una fama que se debe en gran medida al azar por cuanto su obra ha sido el único tratado sobre la producción artística de la Antigüedad clásica que ha sobrevivido, fue un arquitecto que ejerció toda su vida como ingeniero militar y que al final de sus días escribió sobre arquitectura, llevando a cabo una recensión enciclopédica que reune material griego, incorpora bastante de lo romano, y todo ello filtrado por su gusto, que es el de un neoclásico. En su tratado, en el que hay mucho de utopía, se ocupa de la formación del arquitecto, conceptos fundamentales de estética y técnica, aspectos parciales de la construcción, gnómonica, construcciones públicas y privadas, urbanística, orígines de la arquitectura, teoría de los materiales de la construcción, edificación de templos, sus tipos, los órdenes arquitectónicos, teoría de las proporciones, edificios públicos, la vivienda privada, pintura mural y teoría de los colores, construcción de acueductos, la concepción del universo de las ciencias naturales, y construcción de maquinaria y mecánica, siendo una fuente esencial para la reconstrucción de la literatura artística del mundo antiguo. Seixas probablemente utilizaría la edición del traductor Miguel de Urrea, llevada a cabo en Alcalá de Henares por Juan Graciá en $1582^{50}$.

49 «Las Guerras de los Estados Vajos, en un tomo de a quartto». Cfr. PALAU Y DULCET, A.: op. cit., t.III, 569; PEETERS-FONTAINAS, J.: op. cit., t.I, 143-144.

${ }^{50}$ «El maesttro Bittru(vio) de Arquittecttura, en un tomo de a quartto». Sobre el texto vitruviano y sus diferentes ediciones véase BONET CORREA, A.: Bibliografia de arquitectura, ingenieria y urbanismo en España (1498-1880), t.I, Madrid, 1980, 144; CERVERA VERA, L.: El códice de Vitruvio hasta sus primeras versiones impresas, Madrid, 1978; GARCIA MELERO, J.E.: «Las ediciones españolas de «De Architectura» de Vitruvio», Fragmentos, 1986, 102-131; GOMEZ MORENO, M.: El libro español de arquitectura,

"CUADERNOS DE ESTUDIOS GALLEGOS", Tomo XLI, Fascículo 106, Santiago 1993-94. 
Los dos tomos del «Arte y Uso de Arquitectura» de Fray Lorenzo de San Nicolás, constituyen uno de los mejores tratados de instrucción arquitectónica del siglo XVII. El autor, utilizando textos de tratadistas anteriores y sus propias experiencias arquitectónicas, redacta una obra didáctica destinada a los aprendices de la profesión de arquitecto. El primer volumen se ocupa en profundidad de la aritmética, el dibujo, el proceso de edificación, las órdenes arquitectónicas, los arcos, las bóvedas, las fachadas, las conducciones de aguas, las cualidades de un buen maestro de obras, e incluye la traducción del libro I de Euclides. En cambio, el segundo se encarga del estudio de los órdenes arquitectónicos según la opinión de diferentes eruditos, publica, traducidos, los libros V y VII de Euclides, advierte sobre los fraudes corrientes de los maestros de obras, y edita transcritas las antiguas Ordenanzạs de la ciudad de Toledo. La edición príncipe del tomo primero es de 1633 y la del segundo de 1665 , los dos publicados en Madrid, siendo reimpreso el primero en 1667, y ambos conjuntamente en $1736^{51}$.

El «Tratado breve sobre las Ordenanzas de la Villa de Madrid y policia de ella», es de Juan de Torija, maestro arquitecto y aparejador de obras reales. En él se recogen las ordenanzas municipales de la construcción de la capital del Estado, y se enuncian las pautas de conducta que debían seguir los arquitectos en cualquier obra levantada en la ciudad. Fue publicado en 1661 en Burgos y en Madrid. Y reimpreso en 1664 (Burgos) y 1728 (Madrid) $^{52}$.

Madrid, 1949, 10-11; KRUFT, H.-W.: Historia de la teoria de la arquitectura. Desde la Antigüedad hasta el siglo XVIII, Madrid, 1990, 23-34; MARIAS, F.: «Marcus Vitruvius Pollio», Los tratados de arquitectura, Madrid, 1988, 79-80; SCHLOSSER, J.: La literatura artística, Madrid, 1976, 225-231; VENTURI, L.: Historia de la critica del arte, Barcelona, 1979, 61-62.

${ }^{51}$ «Primera y Segunda partte de la Arquittecttura por el Padre Fray Laurencio de San Nicolas, agusttino descalzo, en dos tomos de a folio». Cfr. BONET CORREA, A.: op. cit., t.I, 87-89; Idem: «Fray Lorenzo de San Nicolás», Los tratados de arquitectura, Madrid, 1988, 98-100; CAMARA MUÑOZ, A.: Arquitectura y sociedad en el Siglo de Oro, Madrid, 1990, 162; FERNANDEZ ARENAS, J.: Fuentes y documentos para la historia del arte. Renacimiento y Barroco en España, Barcelona, 1982, 120-123; GARCIA MORALES, M ${ }^{\mathrm{a}}$.V.: La figura del arquitecto en el siglo XVII, Madrid, 1991, 65; GOMEZ MORENO, M.: op. cit., 20-21; KRUFT, H.-W.: op. cit. 299.

${ }_{52}$ «Tratado sobre las Ordenanzas de la Villa de Madrid y Poliçias de ella, en un tomo de a quartto». Cfr. BONET CORREA, A.: op. cit., t.II, 361-362; GARCIA MORALES, Ma.V.: op. cit., 152-156; GOMEZ MORENO, M.: op. cit., 21-22; KRUFT, H.-W.: op. cit., 302.

"CUADERNOS DE ESTUDIOS GALLEGOS", Tomo XLI, Fascículo 106, Santiago 1993-94. 
Las tres obras analizadas presentan algunas características comunes. La primera es su carácter didáctico, con un contenido práctico, utilitario y funcional. Su texto se ha concebido como una ayuda para los maestros de obras cuando tienen que resolver algún problema de índole técnico. Las explicaciones se ilustran con instructivas láminas y de ellas se pueden extraer modelos arquitectónicos y ornamentales para sus intervenciones artísticas.

Los tres autores reivindican, en mayor o menor grado, la primacía de la arquitectura sobre las otras artes e incluso sobre las ciencias. Y tanto Lorenzo de San Nicolás como Torija defienden el concepto de un arquitecto profesional y la realización de un examen para alcanzar tal grado, como hace años después el arquitecto compostelano Domingo de Andrade ${ }^{53}$. Ambos recogen las normas que regulan la profesión del arquitecto, el primero en Toledo y el segundo en Madrid, y que tomarán como modelo en mayor o menor medida el resto de las ciudades del país.

Sólo de un texto del inventario no hemos podido identificar la autoría con seguridad. Se trata del «Artte de arquittecttura, en vn tomo de a folio», obra que quizás se refiera a una de las ediciones españolas de los textos de Serlio ${ }^{54}$, Alberti ${ }^{55}$, Palladio ${ }^{56}$ o Vignola ${ }^{57}$ a los que Seixas pudo tener acceso, aunque por la similitud del título con los dos tomos mencionados del tratado de arquitectura de Fray Lorenzo de San Nicolás no debemos descartar se trate de otro ejemplar duplicado.

${ }^{53}$ Cfr. TAIN GUZMAN, M., op. cit., 44.

${ }^{54}$ SERLIO, S.: Tercero y quarto libro de Architectura de... En los quales se trata de las maneras de como se pueden adornar los hedificios con los exemplos de las antiguedades. Agora nuevamente traduzido de Toscano en Romance Castellano por Francisco Villalpando Architecto, Toledo, Iuan de Ayala, 1552. Reimpreso en 1563 y 1573.

${ }^{55}$ ALBERTI, L.B.: Los diez libros de Architectura de... Traduzidos de Latin en Romance, Madrid, Alonso Gomez, 1582.

${ }^{56}$ PALLADIO, A.: Libro primero de la Architectura de... Que trata de cinco ordenes para fabricar, y otras advertencias. Traduzido de Toscano en Castellano, por Francisco de Praues, Architecto, y Maestro Mayor de las obras de su Magestad, Valladolid, Ivan, Lasso, 1625.

${ }^{57}$ BAROZZIO DA VIGNOLA, G.: Regla de los cinco ordenes de Architectura de... Agora de nuevo traduzido de Toscano en Romance por Patricio Caxesi Florentino, pintor y criado de su Magestad, Madrid, Vicencio Carducho, 1593. Reimpresa en Madrid en $1619,1651,1658,1702,1722$.

"CUADERNOS DE ESTUDIOS GALLEGOS", Tomo XLI, Fascículo 106, Santiago 1993-94. 
Concluyamos señalando la importancia de este tipo documentación para la confección de una sociología del arte gallego. Gracias a ella, no sólo podemos conocer aspectos del taller de un maestro de obras de la primera mitad del siglo XVIII, sino también conocer la biblioteca completa de un maestro menor, que viene a aumentar el conocimiento sobre las bibliotecas compostelanas dieciochescas ${ }^{58}$.

$Y$, aunque pequeña, su estudio es indicativo del tipo de libros que debía utilizar un modesto maestro de obras, en un contexto social donde era difícil reunir una buena colección bibliográfica por su elevado coste económico, lejanía de los centros de impresión, malas comunicaciones con el resto de la península y precario intercambio cultural ${ }^{59}$. Además, los libros nos señalan una faceta muy significativa de la personalidad del propietario, aunque también hay que tener en cuenta el factor de la moda en las lecturas del personaje. Conviene advertir, también, que el poseer una biblioteca no excluye la posibilidad de otras lecturas. Los miembros del mismo gremio podían intercambiarse textos de interés entre $s^{6}{ }^{60}$.

Los textos que Seixas posee sobre la Tercera Orden y el hecho de que solicitase ser enterrado en su capilla compostelana parecen indicar cierta relación del maestro con esta institución. Desgraciadamente, el desconocimiento que tenemos sobre su actividad profesional nos impide evaluar en que medida influyeron todas estas lecturas en su quehacer artístico.

\footnotetext{
${ }^{58}$ Véase BARREIRO MALLON, B.: «Las clases urbanas de Santiago en el siglo XVIII: definición de un estilo de vida y de pensamiento», La historia social de Galicia en sus fuentes de protocolos, Universidad de Santiago, 1981, 471-479. Sobre las bibliotecas compostelanas de los siglos XVI y XVII véanse GELABERT GONZALEZ, J.E.: «La cultura libresca de una ciudad provincial del Renacimiento", La documentación notarial y la historia, Actas del II coloquio de Metodología Histórica Aplicada, Universidad de Santiago, 1984, t.II, 147-163; REY CASTELAO, O.: «El clero urbano compostelano a fines del siglo XVII: mentalidades y hábitos culturales», La historia social de Galicia en sus fuentes de protocolos, Universidad de Santiago, 1981, 508-509, 515-519.

${ }^{59}$ Cfr. CHEVALIER, M.: Lectura y lectores en la España del siglo XVI y XVII, Madrid, 1976, 20 y ss.

${ }^{60}$ En cuanto a la metodología para estudiar el inventario de una biblioteca véase HUARTE MORTON, F.: «Las bibliotecas particulares españolas en la Edad Moderna», Revista de Archivos, Bibliotecas y Museos, 1955, 563.
}

"CUADERNOS DE ESTUDIOS GALLEGOS", Tomo XLI, Fascículo 106, Santiago 1993-94. 